\title{
BDA special care case mix model
}

\author{
IN BRIEF \\ - The model described in this article is \\ becoming recognised and widely used \\ in salaried dental services in UK as a \\ useful methodology for describing the \\ complexity of special care patients. \\ - NHS commissioners are interested \\ in using the model to assist in \\ commissioning these services. \\ - The model has potential for use in \\ research in special care dentistry.
}

\author{
N. Monaghan ${ }^{6}$ and L. Zoitopoulos ${ }^{7}$
}

Routine dental care provided in special care dentistry is complicated by patient specific factors which increase the time taken and costs of treatment. The BDA have developed and conducted a field trial of a case mix tool to measure this complexity. For each episode of care the case mix tool assesses the following on a four point scale: 'ability to communicate', 'ability to cooperate', 'medical status', 'oral risk factors', 'access to oral care' and 'legal and ethical barriers to care'. The tool is reported to be easy to use and captures sufficient detail to discriminate between types of service and special care dentistry provided. It offers potential as a simple to use and clinically relevant source of performance management and commissioning data. This paper describes the model, demonstrates how it is currently being used, and considers future developments in its use.

\section{BACKGROUND}

Patients with disabilities often present complexities to those providing dental care irrespective of the actual dentistry required. Such complexities range from a relatively straightforward need to provide wheelchair access to a surgery to the challenging patient with learning disabilities, a complex medical history and no ability to communicate. ${ }^{1}$

In the UK traditional methods of monitoring and rewarding dentists working in NHS general dental practice such as fee per item and units of dental activity (UDA)

${ }^{1 *}$ Clinical Director of Dental Services, Sheffield PCT, Firth Park Clinic, North Quadrant, Sheffield, S5 6NU; ${ }^{2}$ Dentist, Special Care Dentistry, Halton St Helens NHS Community Dental Services, OPD3 Countess of Chester Hospital, Liverpool Road, Chester, CH2 1UL; ${ }^{3}$ Senior Dental Officer, Community Dental Service, Highlands Community Trust, Royal Northern Infirmary, Ness Walk, Inverness, IV2 7GE; ${ }^{4}$ Senior Community Dentist, Gloucestershire Salaried Primary Care Dental service, St Paul's Medical Centre, 121 Swindon Rd, Cheltenham, GL50 4DP; ${ }^{5}$ Specialist in Paediatric Dentistry, Clinical Director - Gwent Community Dental Service, Dental Dept, Canolfan Ty Newydd, Tudor Road, Cwmbran, Torfaen, Gwent, NP44 3YN; ${ }^{6}$ Consultant in Dental Public Health, National Public Health Service for Wales, Temple of Peace and Health, Cathays Park, Cardiff, CF10 3NW; ${ }^{7}$ Honorary Senior Lecturer and Head of Department, Dept of Community Special Care Dentistry, GKT Dental Institute, Caldecot Road, London, SE5 9RW

${ }^{*}$ Correspondence to: Mr Peter Bateman

Email: peter.bateman@sheffieldpct.nhs.uk

\section{Refereed Paper}

Accepted 19 February 2010

DOI: 10.1038/sj.bdj.2010.294

${ }^{\circ}$ British Dental Journal 2010; 208: 291-296 are based on historic averaging systems. There is a direct linkage between activity undertaken and fees payable. In most cases this makes no allowance for patient complexity and the additional time it may take to undertake a given procedure for such a patient. Where an allowance is payable, such as is currently the case in Scotland, it is questionable how often this covers the costs associated with the complexity. In contrast until recently funding of the salaried dental service (community dental service) and the hospital dental services was not dependent on activity undertaken. As a result complex patients such as those with disabilities or severe anxiety have traditionally accessed care from these services, either directly or as a result of referral by a general dental practitioner.

In recent years the NHS commissioning agenda, where competition for resources and demonstration of value for money are key aims, has increased pressure on such services to demonstrate efficiency and effectiveness as outcome measures. In England the introduction of treatment tariffs in the hospital service, and the creation of a single performers list for all primary care dentists (including those in the salaried services) makes comparison between providers of special care dentistry and other dental providers relatively simple. Without a measure to demonstrate patient complexity a commissioner without in depth knowledge of all aspects of dentistry could, on the basis of routine activity data, view a provider of special care dentistry as inefficient, with the consequent threat to services for such patients.

Kevin Lewis summarised the issues facing special care dentists as follows: 'They are treating patients who present massive challenges by virtue of their physical, mental and/or systemic condition. The difficulties of treating them would be beyond many of us for practical, logistic, and commercial reasons, let alone the fact that this is specialist care requiring an exceptional degree of skill and competence. Is it not staggering, therefore, that they are forced to justify their existence and performance on precisely the same UDA basis as the rest of primary care dentistry.'2

The British Society for Disability and Oral Health in their commissioning tool for special care dentistry noted that 'Contracts must reflect the additional time and resources required to provide care for this group of patients. ${ }^{3}$ The Department of Health (England) in recent guidance on oral health for disabled children and adults, stated 'Some disabled children and adults can present challenges to primary and secondary providers. Delivering a quality service to children and adults who may have poor understanding, uncontrolled 
movements, limited mouth opening, poor posture or limited mobility, who may experience tiredness during treatment or have medical problems, presents a range of difficulties and barriers.' 4 The measures the Department recommends commissioners use to monitor to ensure such patients have appropriate access to dental care include 'An assessment of the degree of difficulty in carrying out dental treatment, based on the individual's impairment or disability and the impact this has on providing a responsive service.'

\section{DEVELOPMENT OF THE CASE MIX MODEL}

The model was developed by a working group at the BDA established by the Central Committee for Community and Public Health Dentistry (CCCPHD). The model measures the complexity of the patient against six criteria:

- Ability to communicate

- Ability to cooperate

- Medical status

- Oral risk factors

- Access to oral care

- Legal and ethical barriers to care.

For each episode of care a patient is measured against each criteria using a four point scale $(\mathrm{OABC})$, where 0 reflects a 'standard' patient and $\mathrm{A}, \mathrm{B}$ and $\mathrm{C}$ represent increased degrees of complexity. The model contains a narrative for each criteria and scale point, and the operator records the 'best fit' as judged over a course of treatment.

For any particular individual patient, each course of treatment is considered separately. For example a patient who requires a general anaesthetic or sedation for dental treatment will score a ' $\mathrm{C}$ ' for Cooperation in all courses where this is provided, but only an 'A' or ' $\mathrm{B}$ ' in a course that involved an examination only and no treatment under GA or sedation. In this way the model more accurately reflects the actual needs of the patient over time than the traditional methods of 'labelling' a patient with a learning disability, mental health problem etc. The model is a descriptive representation of the complexity of the patient and not the dentistry required. It is not a mathematical formula to establish a weighted UDA. The criteria have suggested weightings which can be used to measure relative complexity of different patients or

\section{Table 1 Case mix weightings - complexity and weighting}

\begin{tabular}{|l|l|l|l|l|}
\hline & 0 & A & B & C \\
\hline Ability to communicate & 0 & 2 & 4 & 8 \\
\hline Ability to cooperate & 0 & 3 & 6 & 12 \\
\hline Medical status & 0 & 2 & 6 & 12 \\
\hline Oral risk factors & 0 & 3 & 6 & 12 \\
\hline Access to care & 0 & 2 & 4 & 8 \\
\hline Legal and ethical barriers to care & 0 & 2 & 4 & 8 \\
\hline
\end{tabular}

\section{Table 2 Participants in field trial}

\begin{tabular}{l|l}
\hline Airedale & Mid Hampshire \\
\hline Blackwater Valley \& Hart & North Derbyshire \\
\hline Bradford & North Lincolnshire \\
\hline Bromley & Oxfordshire \\
\hline Calderdale \&t Kirklees & Sheffield \\
\hline Cotswold \& Vale & Shropshire \\
\hline Doncaster & Solihull \\
\hline East Elmbridge \&t Mid Surrey & Southampton \\
\hline Gwent & Surrey Heath \& Woking \\
\hline Halton & Vale of Aylesbury \\
\hline Hambledon \& Richmond & Wiltshire \\
\hline Leeds & Wycombe \\
\hline Lincolnshire & \\
\hline
\end{tabular}

Table 3 Field trial - number of episodes by age

\begin{tabular}{|l|l|l|l|l|l|l|}
\hline Age & $0-4$ & $5-15$ & $16-64$ & $65+$ & $\begin{array}{l}\text { Age not } \\
\text { recorded }\end{array}$ & Total \\
\hline Number of episodes & 693 & 3,840 & 3,012 & 875 & 171 & 8,591 \\
\hline$\%$ of total & 8.1 & 44.7 & 35.1 & 10.2 & 2.0 & 100 \\
\hline
\end{tabular}

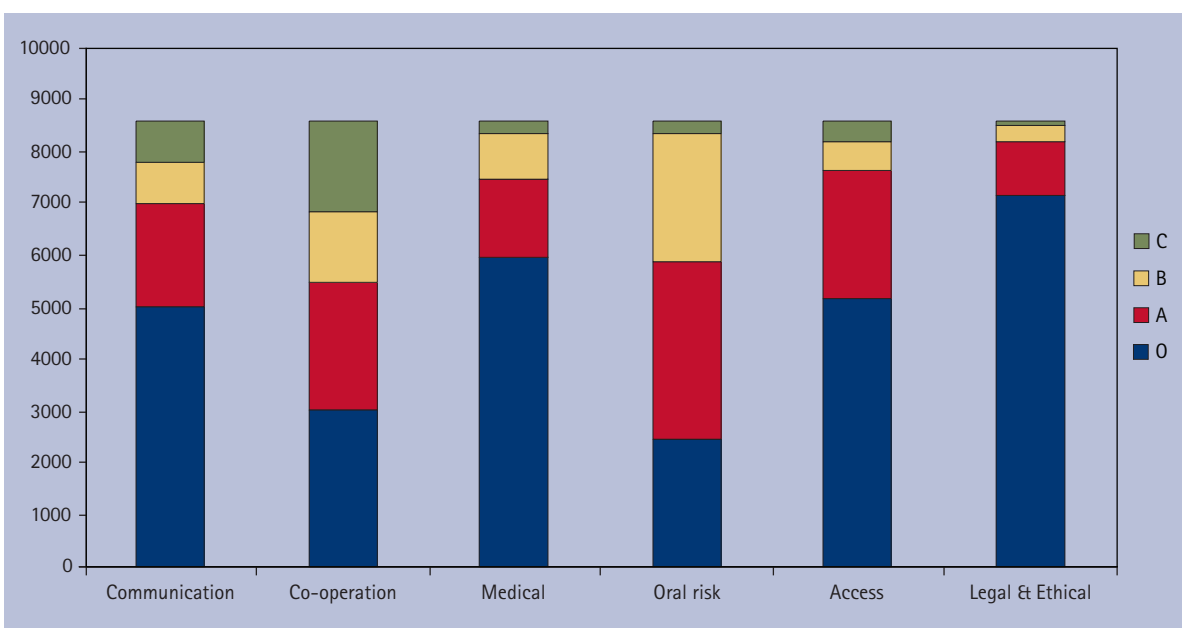

Fig. 1 Field trial - analysis by criteria 


\begin{tabular}{|c|c|c|}
\hline \multicolumn{3}{|c|}{$\begin{array}{l}\text { Table } 4 \text { Field trial - } \\
\text { results of user questionnaire }\end{array}$} \\
\hline \multicolumn{3}{|c|}{$\begin{array}{l}67 \text { replies received } \\
(9 \mathrm{CD}, 30 \mathrm{SDO}, 26 \mathrm{DO}, 2 \mathrm{H} / \mathrm{T})\end{array}$} \\
\hline \multicolumn{3}{|c|}{ Reflects complexity } \\
\hline Yes $\quad 43$ & \multicolumn{2}{|c|}{$43(64 \%)$} \\
\hline No & \multicolumn{2}{|c|}{$10(15 \%)$} \\
\hline Unsure & \multicolumn{2}{|c|}{$14(21 \%)$} \\
\hline \multicolumn{3}{|c|}{ Participate again } \\
\hline & \multicolumn{2}{|c|}{63 (94\%) } \\
\hline \multicolumn{3}{|c|}{ Simple/ Relatively straight forward to use } \\
\hline & & $\%$ \\
\hline Communicate & 54 & 81 \\
\hline Cooperate & 54 & 81 \\
\hline Medical & 57 & 85 \\
\hline Oral risk & 52 & 78 \\
\hline Access & 59 & 88 \\
\hline Legal/Ethical & 51 & 76 \\
\hline Data capture & 57 & 85 \\
\hline
\end{tabular}

of the same patient over different courses of treatment (Table 1). These were based on the experience of the authors, but have since been tested and supported by the field trial participants. Such descriptive models are used elsewhere in dentistry, the visual scale of IOTN being an example.

\section{THE FIELD TRIAL}

The model was based on earlier work undertaken by the CDS in Sheffield which had demonstrated that such an approach appeared to have validity in terms of the different types of patients seen in different clinic settings, and acceptability to staff. Following the initial work on developing the model, an invitation to participate in a field trial went out to salaried dental services in the UK. This invitation was cascaded by members of CCCPHD at the BDA. Services that responded were sent the model with basic instructions on how to collect the data, and a data capture sheet. Data were collected for a two month period between June and August 2006, and all completed data capture sheets sent to PB for analysis. Twenty-five different salaried and community dental services participated in the trial (Table 2). Data were collected on over 8,500 patient episodes of care (Table 3).

Analysis of each of the criteria (Fig. 1) showed a spread of grades had been used across all criteria, with the exception of legal and ethical. The data capture forms themselves told an interesting story of the participating services. Access clinics are clearly distinguishable from special care clinics, and often it was possible to determine precisely the point where one clinic

\section{Table 5 Case mix bandings}

\begin{tabular}{|l|l}
\hline Total case mix score & Band description \\
\hline 0 & No patient complexity \\
\hline $1-9$ & Mild complexity \\
\hline $10-19$ & Moderate complexity \\
\hline $20-29$ & Severe complexity \\
\hline $30+$ & Extreme complexity \\
\hline
\end{tabular}

\begin{tabular}{l|l|l|}
\hline Ability to communicate & C & (No ability) \\
\hline Ability to cooperate & C & (Sedation required) \\
\hline Medical status & B & (Epilepsy unstable) \\
\hline Oral risk factor & B & (OH 3 rd $^{\text {party needed) }}$ \\
\hline Access & A & (Relies on carer) \\
\hline Legal and ethical & B & (Best interests with consultation) \\
\hline Total case mix score 38 & &
\end{tabular}

Fig. 2 Case study A: Peter W is a 32-year-old who has severe learning disabilities. He lives in a unit with 24 hour nursing/support care. Peter does not communicate verbally spending all his time colouring in pictures. Any communication is by vague gestures. It is impossible to examine his teeth except, visually, the anteriors where it is noticed he has copious amounts of calculus on lower incisors. Medically he has epilepsy with seizures weekly, the majority of which are self limiting but occasionally require use of buccal midazolam to control. It is agreed to examine Peter with use of IV sedation in order to examine his posterior teeth and undertake scale and polish. On examination it is noted Peter is caries free with only scaling required

stopped and a different one started.

Following the conclusion of the field trial a simple user questionnaire was devised and sent to clinical directors of participating services, asking them to distribute them to participating staff and return completed forms to PB. In total 67 replies were received (Table 4). The majority of respondents felt the model reasonably reflected the complexity of the patients seen and that it was relatively straightforward to use. Virtually all respondents indicated that they would be willing to participate again if another trial with the model was required. The trial demonstrated that among special care dentists there was a real opportunity for such a model to enable them to demonstrate the value of their work.

Following the field trial the working group amended some of the statements within the criteria narratives, and also added areas that had been identified as missing, for example mental illness. Legal and ethical criteria were clarified, and separate definitions prepared for use in Scotland where the legal basis for treating incompetent adults differs from that in England and Wales.

\section{Routine data collection and analysis}

Three major suppliers of dental software systems in the UK (Practice Works Kodak R4, Software of Excellence SOEL Health, EMIS Dental Systems) have incorporated the model into their software. Users have found recording very simple using the drop down boxes. Data can be recorded at any point during a course of treatment and should be checked before the episode is closed.

During the field trial and in subsequent discussions two popular methods of analysis emerged:

- Banded total weighted score. The weighted scores of the six criteria are totalled, and this gives an overall case mix banding for that patient episode of care (Table 5)

- Maximum score. The data are analysed using only the maximum of the six grades scored for each patient.

The banded score method is recommended when the model is used for benchmarking purposes, for example between different clinicians, clinics or services. It is the method most likely to be 
used when describing the complexity of a service to commissioners. This method requires all users to ensure all six criteria are used appropriately and fully if all aspects of patient complexity are to be accurately demonstrated.

The maximum score method is simpler and more tolerant of a failure to use all criteria as happened to some extent in the field trial. This provides much less differentiation between the different complexities encountered. It may be sufficient for uses such as determining decisions regarding retention on recall or discharge at the end of a course of treatment.

\section{CASE STUDIES}

To support training in using the model, the working group prepared and scored scenarios based on actual cases from their own clinical caseloads. Two scenarios are presented to illustrate different aspects of the model (Figs 2-3).

In Peter's case (Fig. 2) even though the amount of dentistry required is relatively small (in England and Wales value 1 UDA), the amount of resource needed to both treat and maintain his oral health is considerable. This is recognised by the case mix model which awards the highest possible scores in respect of the need for sedation and the challenge of overcoming the lack of direct communication. Considerable engagement of third parties is recognised in each of the other criteria.

In contrast Ernest (Fig. 3) is able to communicate with some difficulty, consent himself and cooperate with treatment. The major complexities are the need to provide care on a domiciliary basis and multipharmacy. Overall the case mix is lower than the first case but still recognises the resource required to complete the examination and consultation.

For training purposes some of the scenarios have been deliberately left open to some interpretation in order to assist new users in thinking through how to apply the criteria. As with many such tools it is easier to apply the criteria after experiencing the challenges of treating an actual patient in comparison to a written scenario. Despite this there was a remarkable level of agreement reached among participants at all three launch events held in January, May and June 2008.

\begin{tabular}{l|l|l|}
\hline Ability to communicate & A & (Some difficulty) \\
\hline Ability to cooperate & A & (Completed exam with some difficulty) \\
\hline Medical status & B & (Complex multipharmacy) \\
\hline Oral risk factor & 0 & \\
\hline Access & C & (Domiciliary) \\
\hline Legal and ethical & 0 & \\
\hline
\end{tabular}

Total case mix score 19

Fig. 3 Case study B: Ernest is 76 and is cared for by his partner with social services input. He has early signs of dementia, and recently had a stroke. He also has had severe arthritis for many years resulting in poor mobility. The referral letter from his GP indicates current medication of a total of 14 different drugs. He is referred because he has lost his dentures and is having difficulty eating. You see him on a domiciliary basis and initially there is some resistance to examination. Ernest indicates he does not want new teeth. After conferring with his partner regarding your concerns about his being able to cope with new dentures, you decide not to proceed and write back to his GP reporting this

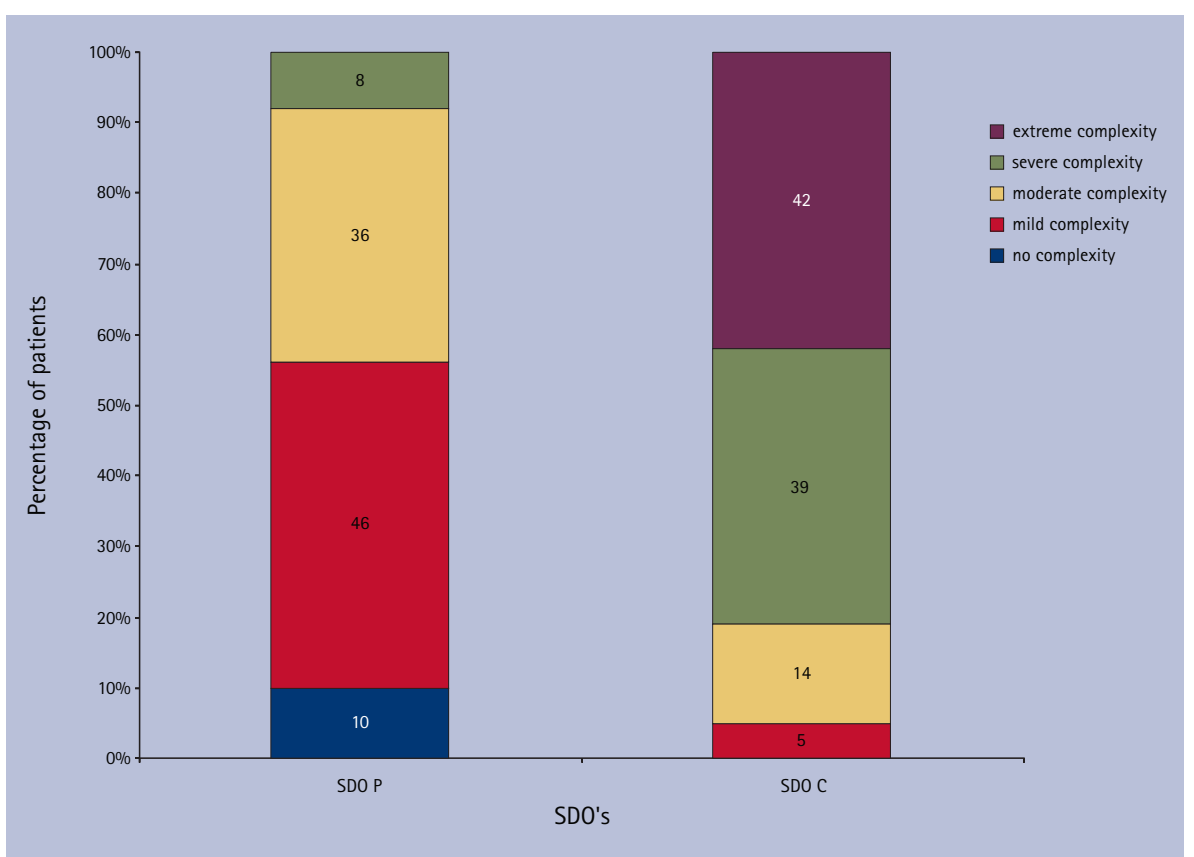

Fig. 4 Comparison of case mix for special care and paediatric SDOs in Halton

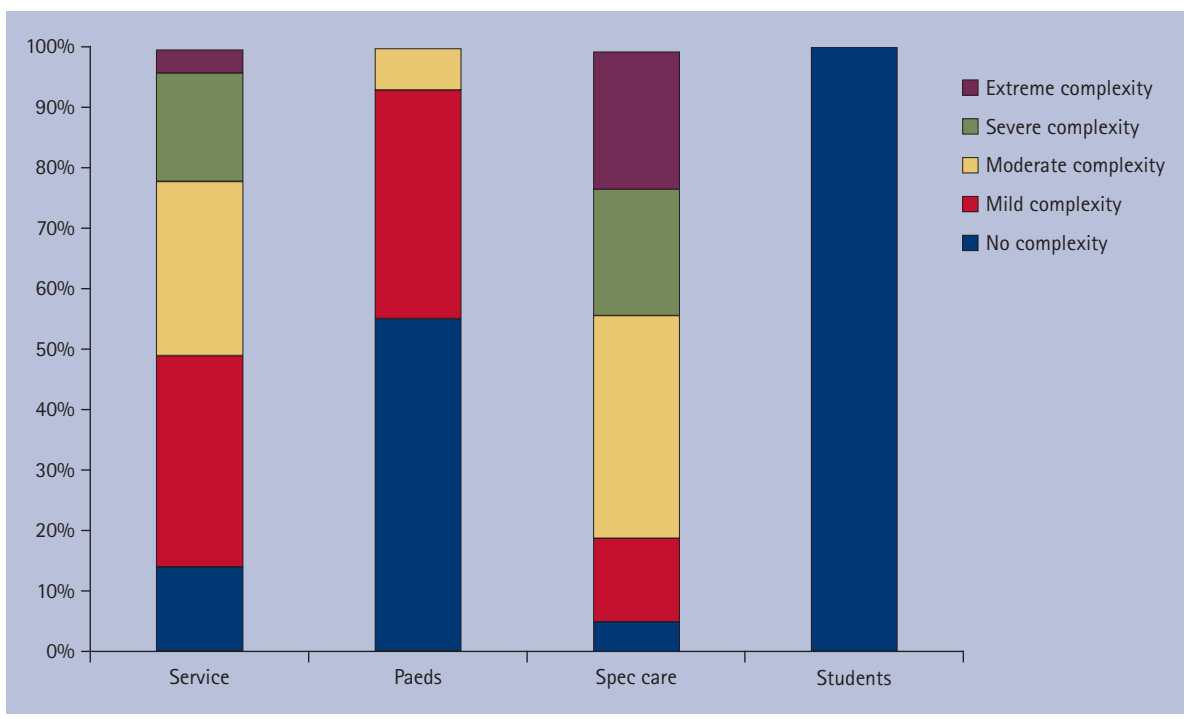

Fig. 5 Complexity of care by service function, Halton 


\section{Use of the data}

Data collected in Halton Salaried Service (Figs 4-5) and in Highland CDS and salaried GDS (Figs 6-7) shows how the information may be used both to compare the workloads of different clinicians and to explain to commissioners the different types of clinic provided.

Figure 4 demonstrates the banded case mix scores of a senior dentist (paediatric dentistry) in comparison to a senior dentist (adult special care) in Halton. While both treat very few 'standard patients' the level of complexity experienced by the adult special care dentist is much greater, and one would expect this to be reflected in their respective activity figures. Figure 5 presents data for the whole service (column 1) subdivided into the three specific functions for which they are commissioned - paediatric dentistry, special care dentistry and outreach teaching. Fourteen percent of the patients seen by the service are 'standard patients' with no complexity. Commissioners may question why such patients are seen by the salaried service but the breakdown provides an explanation. Virtually all the special care dentistry patients are complex. In the paediatric service $50 \%$ of the patients have no case mix complexity, a result one would expect when a significant proportion of the paediatric referrals received are for dental complexities (management of trauma and a specialised clinic for hypodontia) and not behavioural issues. Finally it can be demonstrated that the more straightforward patients are being transferred onto student clinics.

Highland region conducted a pilot of the case mix model in nine clinics between January and March 2008. ${ }^{5}$ Seventeen community dentists and salaried general dental practitioners were included in the study. Figure 6 demonstrates presence of complexities (A, B or C) comparing clinics. In some clinics the majority of patients have multiple complexities, while in others most patients have none or just one or two complexities. This pattern reflects the balance between complex special care patients and general dental access patients in clinics; clinics to the right hand side of the table having a case mix predominantly consisting of special care complex patients.

An interesting aspect of this study was the comparison of the case mix result with

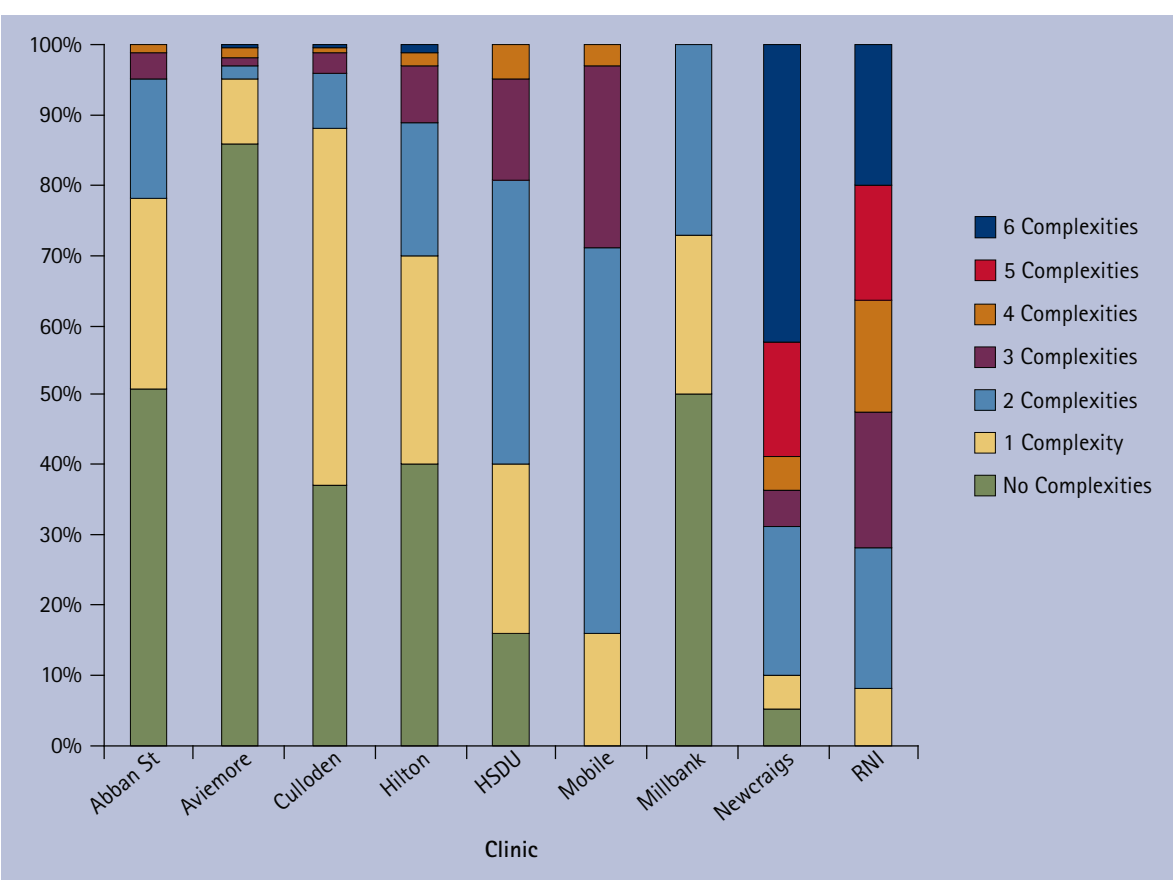

Fig. 6 Number of case mix complexities $>0$ by clinic

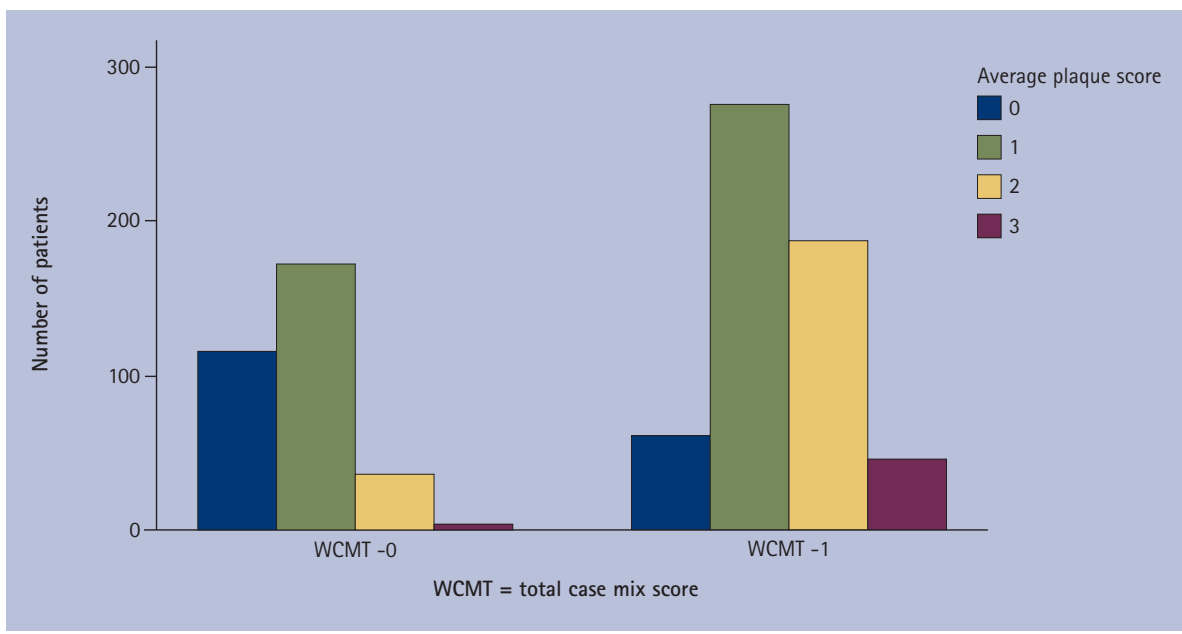

Fig. 7 Plaque score - standard and complex patients

standard oral health indices. Figure 7 compares plaque scores of patients with no complexities with those with one or more complexity. It can be seen that the oral hygiene of patients with one or more complexities is poorer than that of standard patients and demonstrates the potential of the model both as a tool to help practitioners and commissioners gain greater understanding of the services that are provided, and also assist in research into the oral health needs of special care patients.

\section{FUTURE DEVELOPMENT}

It is intended to undertake a further study of use of the model in salaried services in early 2010. Informal communications show that many salaried services have started to collect case mix data as part of their dental records. The first priority for most is to demonstrate to their commissioners the challenges and value of the work they do. Some services have begun to use the criteria to assist in decision making regarding referrals, both at the time of acceptance and at discharge. Individual dentists are using the criteria to demonstrate the complexity of their caseload as part of their portfolio, both for the appraisal system in the recently introduced salaried dentists' contract, and in preparation for applying for mediated entry to the new speciality of special care dentistry. Clinical directors have begun to benchmark dentists and clinics within their areas, both as a performance management tool and to ensure appropriate deployment of resources. 
It was noted during all launch events that there was a high level of consistency of scoring of the participants in the scenario exercise. However, it is acknowledged that as more staff are trained in the use of the model, further work on assessing reliability of the model should be undertaken.

As more services use the data it can only be a matter of time before commissioners start benchmarking one service against another. Such an exercise is not new in NHS management, but case mix will be a much more appropriate measure than those used hitherto.

It was never the intention of the working party that use of case mix be confined to the salaried services. While in the initial development they were the prime users it can be used by general dental practitioners or secondary care providers who are treating special care patients. Its use is not confined to systems where the contract currency is the UDA; it is an equally valid adjunct to any contract currency used to measure volume of dental activity. It is hoped that in time many sectors of the profession will use it to ensure that the needs of special care patients are being appropriately met. It should be noted that the 'legal and ethical barriers to care' area of this tool is sensitive to local laws applying to consent. As a result adaptations to the narrative in this area need to be considered when the model is used outside the UK.

Finally the BDA is currently exploring the possibility of translating the model for use within other professional fields within the health and social care sector, and would be very interested to hear from potential interested parties who may wish to be involved in this work.

\section{CONCLUSIONS}

The case mix model can aid both commissioners and providers of special care dental services to understand the challenges of caring for patients with complexities that impact on provision of dental treatment. Data collection and analysis is relatively easy, and well accepted by dental staff working in this field. It is anticipated that the model will be an important component of the dataset used to monitor dental activity, particularly for special care patients. It also can be used in assisting practitioners and services to establish appropriate referral pathways, and has the potential to support research in special care dentistry.

1. Fiske J, Dougall A. Access to special care dentistry, part 1. Access. Br Dent J 2008; 204: 605-616.

2. Lewis K. Does my contract value look big in this? Dentistry 2007 April 5. pp3

3. British Society for Disability and Oral Health. Commissioning tool for Special Care Dentistry. 2006

4. Department of Health. Valuing people's oral health a good practice guide for improving the oral health of disabled children and adults. 21 November 2007.

5. Hally J, Freeman R. A field trial conducted in the Salaried Dental Services NHS Highland. Personal communication.

\section{Erratum}

\section{CPD questions (BDJ 2010; 208: 232)}

It has been brought to our attention that in $B D J$ volume 208 issue 5, CPD Article 1 question 3 read as follows:

3. In the results of this study:

A. all scores showed significantly higher satisfaction for patients attending dentists

B. in Practice 5 all dentists refer to dental therapists

C. there were three dental therapists in Practice 3

D. the mean patient satisfaction score for therapists' technical competence was 18.56

In this version of the question, both options B and D were correct. Option D should have read: "the mean patient satisfaction score for therapists' technical competence was 17.18'.

A notice was posted on the Eastman CPD website as soon as the error came to our attention.

We apologise for any inconvenience caused. 